\title{
Article
}

\section{Highly crystalline carbon nitride hollow spheres with enhanced photocatalytic performance}

\author{
Yang Li a,b, Dainan Zhang a, Jiajie Fan c, Quanjun Xiang a,* \\ a State Key Laboratory of Electronic Thin Film and Integrated Devices, School of Electronic Science and Engineering, University of Electronic Science and \\ Technology of China, Chengdu 610054, Sichuan, China \\ b College of Resources and Environment, Huazhong Agricultural University, Wuhan 430070, Hubei, China \\ ' School of Materials Science and Engineering, Zhengzhou University, Zhengzhou 450002, Henan, China
}

\section{A R T I C L E I N F}

\section{Article history:}

Received 26 May 2020

Accepted 11 July 2020

Available online 5 September 2020

Keywords:

Crystalline

Hollow spheres

Graphitic carbon nitride

Photocatalytic hydrogen evolution

Photocatalytic degradation

Plasticizer

\begin{abstract}
A B S T R A C T
Graphitic carbon nitride $\left(\mathrm{g}-\mathrm{C}_{3} \mathrm{~N}_{4}\right)$ has emerged as a remarkably promising photocatalyst for addressing environmental and energy issues; however, it exhibits only moderate photocatalytic activity because of its low specific surface area and high recombination of carriers. Preparation of crystalline $\mathrm{g}-\mathrm{C}_{3} \mathrm{~N}_{4}$ by the molten salt method has proven to be an effective method to improve the photocatalytic activity. However, crystalline g- $\mathrm{C}_{3} \mathrm{~N}_{4}$ prepared by the conventional molten salt method exhibits a less regular morphology. Herein, highly crystalline g- $\mathrm{C}_{3} \mathrm{~N}_{4}$ hollow spheres (CCNHS) were successfully prepared by the molten salt method using cyanuric acid-melamine as a precursor. The higher crystallization of the CCNHS samples not only repaired the structural defects at the surface of the CCNHS samples but also established a built-in electric field between heptazine-based g- $\mathrm{C}_{3} \mathrm{~N}_{4}$ and triazine-based $\mathrm{g}-\mathrm{C}_{3} \mathrm{~N}_{4}$. The hollow structure improved the level of light energy utilization and increased the number of active sites for photocatalytic reactions. Because of the above characteristics, the as-prepared CCNHS samples simultaneously realized photocatalytic hydrogen evolution with the degradation of the plasticizer bisphenol A. This research offers a new perspective on the structural optimization of supramolecular self-assembly.
\end{abstract}

(C) 2021, Dalian Institute of Chemical Physics, Chinese Academy of Sciences. Published by Elsevier B.V. All rights reserved.

\section{Introduction}

With the development of photocatalysts, photocatalysis for hydrogen evolution from water has attracted more and more attention for dealing with environmental pollution and the energy crisis [1-6]. As a metal-free photocatalyst, polymeric graphitic carbon nitride $\left(\mathrm{g}-\mathrm{C}_{3} \mathrm{~N}_{4}\right)$ is the most promising candidate in the field of photocatalysis because of its good electronic structure, unique optical properties, appealing thermal and chemical stability, and benign environmental behavior [7-10]. However, low specific surface area and rapid recombination of charge carriers as well as less accessible active surface sites have greatly limited the application of conventional g- $\mathrm{C}_{3} \mathrm{~N}_{4}$ in photocatalytic water splitting [11-14]. Fortunately, extensive strategies, such as nanostructure design $[15,16]$, heteroatom doping $[17,18]$, and increasing the crystallinity [19-21], have been developed to significantly mitigate these issues to improve the photocatalytic performance of conventional g- $\mathrm{C}_{3} \mathrm{~N}_{4}$. In particular, increasing the crystallinity of conventional g- $\mathrm{C}_{3} \mathrm{~N}_{4}$ has attracted significant attention because highly crystallized g- $\mathrm{C}_{3} \mathrm{~N}_{4}$ (CCN) can improve the migration of charge carriers owing to the much denser packing of the layers and smaller num-

\footnotetext{
*Corresponding author. Tel/Fax: +86-28-83207063; E-mail: xiangqj@uestc.edu.cn

This work was supported by the Natural Science Foundation of China (51672099, 21403079), Sichuan Science and Technology Program (2019JDRC0027), and Fundamental Research Funds for the Central Universities (2017-QR-25).

DOI: 10.1016/S1872-2067(20)63684-1 | http://www.sciencedirect.com/science/journal/18722067 | Chin. J. Catal., Vol. 42, No. 4, April 2021
} 
ber of defects [22-24]. More strikingly, CCN prepared by the molten salt method exhibits the above-mentioned characteristics, and the doping of potassium $(\mathrm{K})$ ions in the CCN frameworks can further improve the mobility of charge carriers because the $\mathrm{K}$ ions can replace the bridging $\mathrm{N}$ atoms for photogenerated electron transfer between structural units [25,26]. However, CCN prepared by the molten salt method still has some shortcoming, such as a low specific surface area and few accessible active sites, due to the relatively low level of morphology regulation of the nanostructures [27]. Therefore, the preparation of CCN with regular nanostructures by the molten salt method for improving the specific surface area and number of active sites, and therefore providing enhanced photocatalytic activity, is still an enormous challenge.

As is known, the precursor of CCN prepared by the molten salt method is usually a stacked bulk carbon nitride [28,29]. Even though the surface of the resulting sample is crystallized, carbon nitride located within the stacked bulk structure is prevented from forming crystalline carbon nitride and instead forms an irregular structure, resulting in a low specific surface area and incomplete crystallization. Therefore, it is very important to find a new precursor to synthesize regular CCN with complete crystallization. The cyanuric acid-melamine (CM) complex can act as the precursor of $\mathrm{g}-\mathrm{C}_{3} \mathrm{~N}_{4}$ and is typically prepared by precipitation from an equimolecular mixture in a solvent [30-32]. In particular, the CM complex with a 3D spherical structure made up of flake sheets was obtained with the solvent dimethyl sulfoxide (DMSO) [33]. However, g- $\mathrm{C}_{3} \mathrm{~N}_{4}$ formed from the 3D spherical structure has poor crystallinity and many structural defects $[34,35]$. If the CM complex with a 3D spherical structure is used as a precursor for CCN, it will not only repair the surface structural defects but also further increase the specific surface area. Therefore, this 3D spherical structure with a large specific surface area is a suitable alternative to stacked bulk carbon nitride for preparing CCN with a 3D spherical structure.

In addition, a photocatalytic reaction is composed of reduction and oxidation reactions, which are dominated by photogenerated electrons and holes, respectively. These two reactions are complementary, which indicates that the acceleration of any one reaction process will promote the progress of the other reaction. Therefore, sacrificial agents are added to the photocatalytic hydrogen evolution reaction because they can prevent the oxidation reaction process and further accelerate hydrogen generation. However, the sacrificial agents are generally based on alcohols, which are extracted from food [36,37]. Therefore, using biomass and plasticizers as sacrificial agents is currently the best solution. Bisphenol A (BPA) is widely used as a plasticizer in the manufacture of various plastics; however, it exhibits toxicity that endangers human health [38]. The addition of BPA to the photocatalytic hydrogen production reaction not only promotes the production of hydrogen but also degrades toxic pollutants, which is an ideal model for photocatalytic reactions.

Herein, highly crystalline g- $\mathrm{C}_{3} \mathrm{~N}_{4}$ hollow spheres (CCNHS) were successfully prepared for the first time by using $\mathrm{CM}$ as the precursor for the molten salt method. The CCNHS samples presented a unique hollow spherical structure with a nanorod morphology on the surface and simultaneously realized photocatalytic hydrogen evolution with the degradation of the plasticizer BPA. Moreover, a built-in electric field was spontaneously established in the CCNHS sample owing to the presence of heptazine-based and triazine-based g- $\mathrm{C}_{3} \mathrm{~N}_{4}$. Because of these features, the as-prepared CCNHS samples have a highly regulated hollow spherical morphology, a high specific surface area of $185.6 \mathrm{~m}^{2} \cdot \mathrm{g}^{-1}$, a photocatalytic hydrogen production of 151.2 $\mu \mathrm{mol} \cdot \mathrm{h}^{-1} \cdot \mathrm{g}^{-1}$, and good BPA degradation.

\section{Experimental}

\subsection{Materials}

Analytical-grade melamine $\left(\mathrm{C}_{3} \mathrm{H}_{6} \mathrm{~N}_{6}, 99 \%\right)$, cyanuric acid $\left(\mathrm{C}_{3} \mathrm{H}_{3} \mathrm{~N}_{3} \mathrm{O}_{3}, 99 \%\right)$, dimethyl sulfoxide (DMSO), $\mathrm{KCl}$ (99.5\%), and $\mathrm{LiCl}(97 \%)$ were used without further purification. Deionized water was used in all experiments.

\subsection{Sample preparation}

\subsubsection{Synthesis of CM-CN samples}

In a typical procedure, $0.5 \mathrm{~g}$ of cyanuric acid and $0.5 \mathrm{~g}$ of melamine were dissolved in $10 \mathrm{~mL}$ and $20 \mathrm{~mL}$ of DMSO, respectively. After stirring for $10 \mathrm{~min}$, the melamine solution was added to the cyanuric acid solution drop by drop, and then the mixture was stirred for $0.5 \mathrm{~h}$. Subsequently, a white precipitate was obtained by centrifugation and collection after drying overnight at $60{ }^{\circ} \mathrm{C}$ in an oven. The obtained sample is referred to as the CM complex. Finally, $5 \mathrm{~g}$ CM complex was heated to $500{ }^{\circ} \mathrm{C}$ for $4 \mathrm{~h}$ at $2^{\circ} \mathrm{C} \cdot \mathrm{min}^{-1}$ under an air atmosphere in a muffle furnace. The obtained sample is referred to as CM-CN.

\subsubsection{Synthesis of crystallized $g-C_{3} N_{4}$ hollow spheres (CCNHS)}

Typically, $600 \mathrm{mg}$ of the CM-CN samples were ground with $\mathrm{KCl}$ (3.3 g) and $\mathrm{LiCl}$ (2.7 g) in a crucible. Then, the mixture was heated to $550{ }^{\circ} \mathrm{C}$ for $4 \mathrm{~h}$ at $5{ }^{\circ} \mathrm{C} \cdot \mathrm{min}^{-1}$ under an air atmosphere in a muffle furnace. The product was washed with boiling water and collected after drying overnight at $60{ }^{\circ} \mathrm{C}$ in an oven. The obtained sample is referred to as CCNHS.

\subsection{Characterization}

The X-ray diffraction (XRD) patterns were recorded on a D8-Advance diffractometer (Bruker, German) with Ni-filtered $\mathrm{Cu} K_{\alpha}$ radiation at a scan rate $(2 \theta)$ of $10^{\circ} \mathrm{min}^{-1}$, an accelerating voltage of $40 \mathrm{kV}$, and a current of $40 \mathrm{~mA}$. The transmission electron microscopy (TEM) images were obtained using a Hitachi H-7650 (HITACHI, Japan) transmission electron microscope at an accelerating voltage of $200 \mathrm{kV}$, and high-resolution TEM (HRTEM) analysis was performed on a JEM-2100F (JEOL, Japan) microscope. The scanning electron microscopy (SEM) images were collected on an S-4800 (HITACHI, Japan). The UV-vis diffuse reflectance spectra were recorded using a UV-vis spectrophotometer (Lambda 650s), and Teflon was used as the reflectance standard. ${ }^{13} \mathrm{C}$ MAS NMR spectra were collected us- 
ing a Bruker Avance-300 spectrometer with a $4 \mathrm{~mm}$ zirconia rotor. Elemental analysis was performed using a Vario Micro cube elemental analyzer manufactured by Elementar. X-ray photoelectron spectroscopy (XPS) spectra were recorded using a Leybold Heraeus-Shenyang SKL-12 X-ray photoelectron spectrometer, and $\mathrm{Mg} K_{\alpha}$ served as the excitation source. Electron paramagnetic resonance (EPR) spectra were obtained using an EPR spectrometer (Bruker, German) at room temperature. The time-resolved fluorescence decay spectra were measured at room temperature on a fluorescence spectrophotometer (Edinburgh, FS5). The photoelectrochemical measurements were performed on a CHI660E electrochemical workstation (Shanghai Chenhua Co., Ltd., China) equipped with a three-electrode system. The preparation of the sample working electrode was consistent with previous reports [25].

The photocatalytic production of $\mathrm{H}_{2}$ of the obtained photocatalysts was measured in a $100 \mathrm{~mL}$ three-necked flask at atmospheric pressure and room temperature. A $350 \mathrm{~W}$ Xe arc lamp was utilized as the light source, and a BPA solution (10 $\mathrm{mg} \cdot \mathrm{L}^{-1}$ ) was used as the sacrificial agent. The detailed steps were as follows: $20 \mathrm{mg}$ of a sample was dispersed in $80 \mathrm{~mL}$ of sacrificial agent by loading 3\% platinum (Pt) as the cocatalyst. The suspension of photocatalysts was degassed using $\mathrm{N}_{2}$ for 30 min to remove the remaining $\mathrm{O}_{2}$ and air in the flask. After $1 \mathrm{~h}$ of illumination, $0.4 \mathrm{~mL}$ of gas was extracted and detected in a gas chromatograph (GC-2004C, Japan).

The wavelength-dependent hydrogen evolution rate (HER) of the as-prepared samples was determined using a method similar to that for the photocatalytic $\mathrm{H}_{2}$ production. The Xe arc lamp light source was replaced with an LED equipped with different monochromatic lights. The average irradiation intensity of the different monochromatic lights, achieved by controlling the internal power, was $80 \mathrm{~mW} \cdot \mathrm{cm}^{-2}$. Quantum efficiency (QE) was calculated by the Nether equation:

$$
\begin{aligned}
& \mathrm{QE}(\%)=\text { number of reacted electrons/ } \\
& \text { number of incident photons } \times 100 \% \\
= & \left(\text { number of evolved } \mathrm{H}_{2} \text { molecules } \times 2\right) / \\
& \text { number of incident photons } \times 100 \%
\end{aligned}
$$

The phase content of CCNHS can be calculated from the integrated intensities of the (002) peaks of heptazine-based g- $\mathrm{C}_{3} \mathrm{~N}_{4}$ and triazine-based $\mathrm{g}-\mathrm{C}_{3} \mathrm{~N}_{4}$ in CCNHS by using the Nether equation as follows:

$$
\begin{aligned}
& R_{\mathrm{H}}=k A_{\mathrm{H}} /\left(k A_{\mathrm{H}}+A_{\mathrm{T}}\right) \\
& R_{\mathrm{T}}=A_{\mathrm{T}} /\left(k A_{\mathrm{H}}+A_{\mathrm{T}}\right)
\end{aligned}
$$

where $R_{\mathrm{H}}$ and $R_{\mathrm{T}}$ represent the weight fraction of heptazine-based $\mathrm{g}-\mathrm{C}_{3} \mathrm{~N}_{4}$ and triazine-based $\mathrm{g}-\mathrm{C}_{3} \mathrm{~N}_{4}$, respectively, and $A_{\mathrm{H}}$ and $A_{\mathrm{T}}$ are the integrated intensities of the heptazine-based g- $\mathrm{C}_{3} \mathrm{~N}_{4}$ (002) and triazine-based g- $\mathrm{C}_{3} \mathrm{~N}_{4}$ (002) peaks, respectively. Their integrated intensities were obtained by fitting their XRD pattern; $k$ is the coefficient $(0.884)[39,40]$.

\section{Results and discussion}

A typical molten salt synthesis strategy was used to synthesize CCNHS, which was similar to the traditional molten salt method (Fig. 1). In brief, the CM complex was first fabricated by the self-assembly of cyanuric acid and melamine in the DMSO

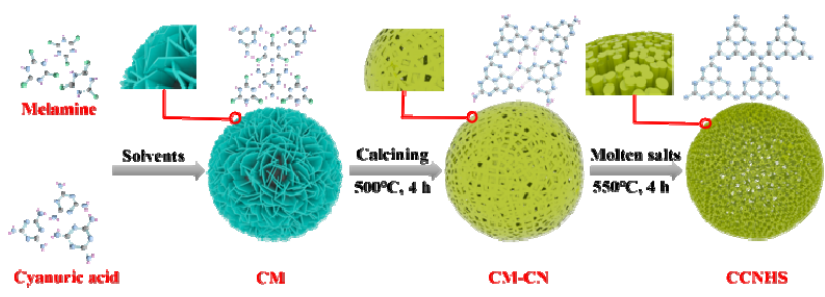

Fig. 1. Schematic diagram of synthesis process over CCNHS samples by using the $\mathrm{CM}$ as a precursor by molten salts method and the corresponding morphological structure and chemical molecular structure of as-prepared samples.

solvents. Then, the CM-CN was formed by calcining the CM complex at $500^{\circ} \mathrm{C}$. Finally, the $\mathrm{CM}-\mathrm{CN}$ was utilized as the precursor to synthesize CCNHS by the molten salt method. The reason for the formation of the CCNHS sample is that the molten salt method can provide a liquid phase reaction environment for the $\mathrm{g}-\mathrm{C}_{3} \mathrm{~N}_{4}$ that decreases the kinetic hindrance, thereby increasing its crystallinity. The SEM investigation (Fig. S1(a)) shows that the morphology of the CM complex is a regular spherical structure with an average diameter of approximately 2-3 $\mu \mathrm{m}$. Further observation (Fig. S1(b)) shows that the spherical structure was composed of a nanosheet structure with a thickness of around $30 \mathrm{~nm}$, and the nanosheet structure had a hexagonal symmetry. The formation of the nanosheet structure is attributed to supramolecular self-assembly of cyanuric acid and melamine, as shown in Fig. 1. The structure of the CM-CN sample obtained by calcining the CM complex was significantly different compared with the CM complex. The solid spherical structure became a hollow spherical structure, and the regular hexagonal nanosheet structure was also replaced by a random porous nanosheet structure (Figs. 2(a), (b) and Figs. S2(a), (b)). This phenomenon indicates that an abundance of bubbles were formed during the calcination of the CM complex, which not only changed the solid spherical structure into a hollow spherical structure but also left a large number of porous structures on the sheet as a soft template. The TEM investigation further confirmed that $\mathrm{CM}-\mathrm{CN}$ is a spherical structure with a porous nanosheet structure on the surface. HRTEM images reveal that no lattice fringes were found for the $\mathrm{CM}-\mathrm{CN}$ samples; there is only one wide diffraction ring in the FFT, and no diffraction spots are present (Fig. 2(g)). This phenomenon indicates that the CM-CN frameworks have an ordered structure, but this ordered structure did not form crystalline g- $\mathrm{C}_{3} \mathrm{~N}_{4}$. In other words, $\mathrm{CM}-\mathrm{CN}$ is an amorphous $\mathrm{g}-\mathrm{C}_{3} \mathrm{~N}_{4}$. From the structures of the $\mathrm{g}-\mathrm{C}_{3} \mathrm{~N}_{4}$ and $\mathrm{CM}$ complex, it can be inferred that the ordered structure in the $\mathrm{CM}-\mathrm{CN}$ frameworks was the heptazine unit, and the formation of amorphous CM-CN should be attributed to the partial hydrogen bond and the residue of the amino group due to the solid-state kinetic hindrance [41]; the structural model of the CM-CN frameworks is shown in Fig. 1. As shown in Figs. 2(c) and (d), the morphology of the CCNHS samples maintained a hollow spherical structure. The biggest difference is that the hollow spherical structure is composed of a nanorod structure compared with the CM-CN sample (Figs. S3 and S4). The HRTEM measurement was used 


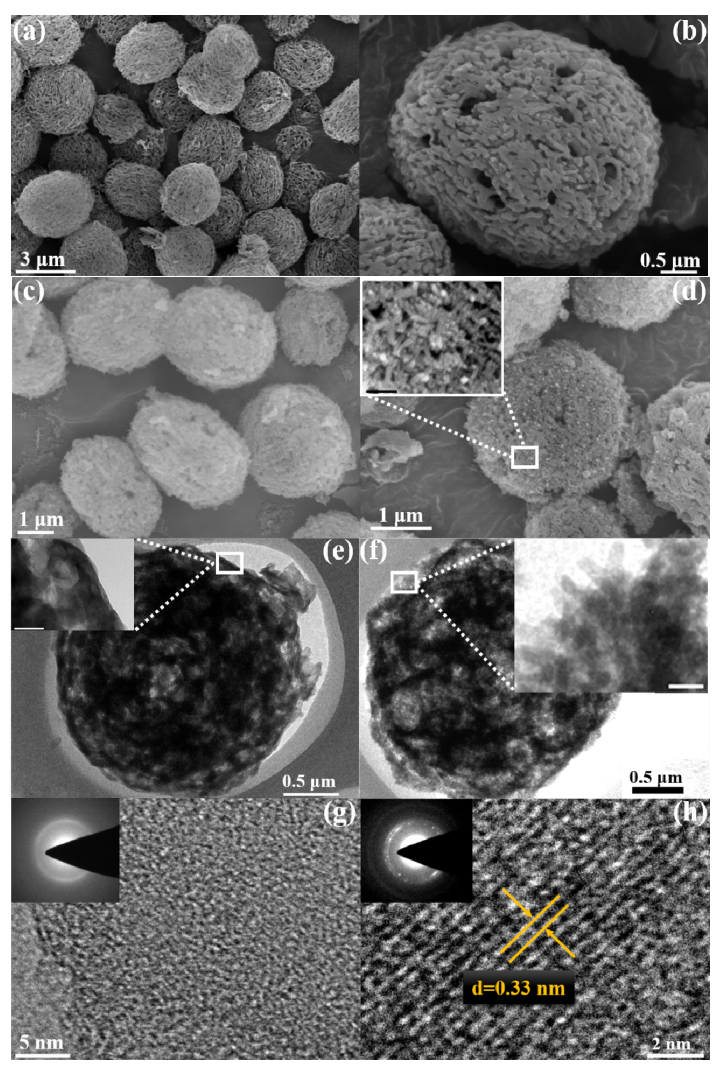

Fig. 2. (a, b) SEM images of CM-CN; (c, d) SEM images of CCNHS, the scale bar of the inset in (d) is $100 \mathrm{~nm}$; (e, g) HRTEM images of CM-CN, the scale bar of the inset in (e) is $100 \mathrm{~nm}$; (f, h) HRTEM images of CCNHS, the scale bar of the inset in (f) is $50 \mathrm{~nm}$.

to further demonstrate the morphology and crystalline structure. As shown in Fig. 2(f), the hollow spherical structure of CCNHS samples consisted of nanorods, and clear lattice fringes of $0.33 \mathrm{~nm}$ and sharp FFT diffraction spots (Fig. 1(h)) were found in the CCNHS samples, suggesting the formation of crystalline g- $\mathrm{C}_{3} \mathrm{~N}_{4}$. In addition, nitrogen sorption analysis (Fig. S5 and Table 1) indicates that the obtained CM-CN and CCNHS samples had a BET surface area of 60.46 and $185.6 \mathrm{~m}^{2} \cdot \mathrm{g}^{-1}$ and a pore volume of 0.209 and $0.689 \mathrm{~cm}^{3} \cdot \mathrm{g}^{-1}$, respectively. The larger specific surface area not only increases the contact area between the photocatalytic samples and water but also increases the number of active sites on the surface of photocatalytic samples, thus enhancing the photocatalytic activity of as-prepared samples.

$\mathrm{XRD}$ analysis was used to analyze the phase structure of the as-prepared samples. As shown in Fig. 3(a), the XRD pattern of the CM-CN samples is similar to that of conventional bulk g- $\mathrm{C}_{3} \mathrm{~N}_{4}(\mathrm{BCN})$, and the two diffraction peaks at $13.0^{\circ}$ and $27.4^{\circ}$ correspond to the (100) plane and the (002) plane, respectively [42]. Interestingly, many diffraction peaks appeared on the XRD patterns of the CCNHS samples (Fig. S6). According to previous research $[43,44]$, these diffraction peaks correspond to heptazine-based and triazine-based g- $\mathrm{C}_{3} \mathrm{~N}_{4}$. Compared with the BCN, the (100) and (002) peak positions of the CCNHS samples are shifted from $13.0^{\circ}$ and $27.4^{\circ}$ to $8.1^{\circ}$ and $28.3^{\circ}$, which correspond to the enlarged in-plane repeating motifs and decreased interlayer distance, respectively $[45,46]$. There may be two
Table 1

Textural properties and chemic composition of the as-prepared samples.

\begin{tabular}{lcccccc}
\hline Samples & FWHM $_{(002)}{ }^{\mathrm{a}}$ & $\begin{array}{c}\text { Surface } \\
\text { area }^{\mathrm{b}} \\
\left(\mathrm{m}^{2} \mathrm{~g}^{-1}\right)\end{array}$ & $\begin{array}{c}\text { Pore } \\
\text { volume }^{\mathrm{b}} \\
\left(\mathrm{cm}^{3} \mathrm{~g}^{-1}\right)\end{array}$ & $\begin{array}{c}\mathrm{C}{ }^{\mathrm{c}} \\
\text { (Atom\%) }\end{array}$ & $\begin{array}{c}\mathrm{Nc} \\
\text { (Atom\%) }\end{array}$ & N/C d \\
\hline CCNHS & 1.043 & 185.6 & 0.689 & 32.77 & 46.78 & 1.43 \\
CM-CN & 2.455 & 60.46 & 0.209 & 35.82 & 56.51 & 1.58 \\
BCN & 1.470 & 13.12 & 0.081 & 38.67 & 57.45 & 1.48 \\
\hline
\end{tabular}

${ }^{\mathrm{a} F W H M}(002)$ is obtained by fitting the as-prepared samples (002) peaks of heptazine phase.

bSurface area and pore volume calculated from desorption branch of nitrogen sorption by BJH method.

${ }^{\mathrm{c}} \mathrm{N}$ and $\mathrm{C}$ (atom\%) is determined by elemental analysis using a Vario Micro cube elemental analyzer manufactured by Elementar.

${ }^{\mathrm{d}} \mathrm{N} / \mathrm{C}$ : the relative ratio of $\mathrm{N}$ and $\mathrm{C}$ elemental in the content.

reasons for this phenomenon: firstly, although the peak for the triazine units is not shown in the XRD pattern of the CM-CN samples, it may be because the number of triazine units in the CM-CN samples was low, and the presence of triazine units was not detected. Therefore, triazine-based $\mathrm{g}-\mathrm{C}_{3} \mathrm{~N}_{4}$ was formed when the precursor containing triazine units was calcined in the molten salt method. Secondly, in an air atmosphere, the oxygen atoms can bind to the carbon in the heptazine unit, thus destroying the structure of the heptazine unit and breaking it into triazine units. Therefore, triazine-based g- $\mathrm{C}_{3} \mathrm{~N}_{4}$ still exists in CCNHS samples. The phase content of the CCNHS samples can be calculated from equation (2). The results show that $52 \%$ of the CCNHS samples were triazine-based $\mathrm{g}-\mathrm{C}_{3} \mathrm{~N}_{4}$ and $48 \%$ were heptazine-based $\mathrm{g}-\mathrm{C}_{3} \mathrm{~N}_{4}$. The full width at half-maximum (FWHM) of the (002) peaks of as-prepared samples was calculated and is presented in Table 1. The FWHM(002) of the CM-CN samples was 2.455, which is larger than that of the BCN samples (1.47). The CCNHS samples have the narrowest FWHM(002) (1.043) relative to the $\mathrm{BCN}$ and $\mathrm{CM}-\mathrm{CN}$ samples. These results demonstrate that the crystallinity of the CCNHS samples was higher than that of the BCN and CM-CN samples, which is consistent with the previous results. The heptazine and triazine units in the CCNHS frameworks were further investigated by FTIR (Fig. S7) and solid-state ${ }^{13} \mathrm{C}$ CP-MAS NMR analysis (Fig. 3(b)). As shown in Fig. 3(b), the chemical shifts appear at 164.3 and $156.6 \mathrm{ppm}$ in the NMR curve, which correspond to the $\mathrm{C}(\mathrm{e})$ atoms $\left(\mathrm{C}-\mathrm{N}-\mathrm{H}_{2}\right)$ and $\mathrm{C}(\mathrm{i})$ atoms $\left(\mathrm{C}-\mathrm{N}_{3}\right)$, respectively [47]. These results demonstrate the existence of heptazine units in the CCNHS and CM-CN frameworks. The specific content of carbon and nitrogen in the samples were further studied by elemental analysis (Table 1). It is worth noting that the $\mathrm{N} / \mathrm{C}$ ratio decreased from 1.58 (CM-CN) to 1.43 (CCNHS), which indicates a decrease in the nitrogen content in the CCNHS samples. This phenomenon may be caused by the nitrogen vacancies formed during the crystallization of the CM-CN samples. This above result is further proved by the XPS N $1 s$ spectrum (Fig. S8 and Fig. 3(c)). As shown in Fig. 3(c), three are three main peaks at 398.6, 399.7, and $401.0 \mathrm{eV}$, corresponding to $\mathrm{C}-\mathrm{N}=\mathrm{C}, \mathrm{N}-(\mathrm{C})_{3}$, and $\mathrm{C}-\mathrm{NH}$, respectively. However, the peak at $401.0 \mathrm{eV}$ disappears in the CCNHS sample, indicating that the reduced nitrogen content should be attributed to a decrease in the NH functional groups, which proves that the crystallinity of the CCNHS 

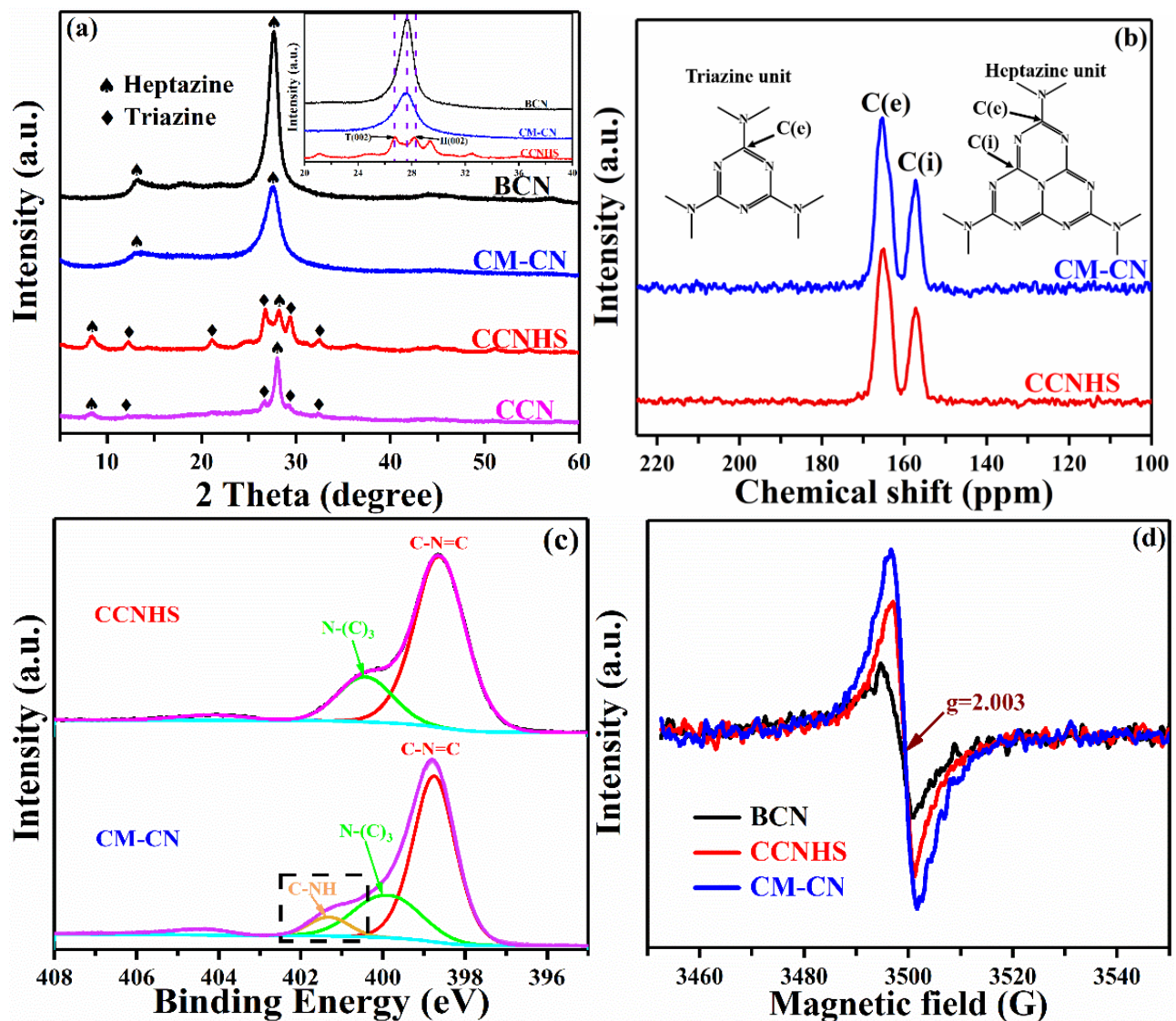

Fig. 3. (a) XRD patterns of the as-prepared samples; (b) solid-state ${ }^{13} \mathrm{C}$ CP-MAS NMR analysis of CM-CN and CCNHS samples; (c) N $1 s$ spectra of CM-CN and CCNHS; (d) EPR spectra of the as-prepared BCN, CM-CN and CCNHS samples.

sample improved. The structural defects of the as-prepared samples were analyzed with the EPR spectra (Fig. 3(d)). The EPR symmetrical signal at $g=2.003$ is ascribed to the existence of unpaired electrons on aromatic rings $[48,49]$, which result from the formation of partial defects in the as-prepared samples. Obviously, the EPR signal of the CM-CN samples is the strongest, followed by CCNHS samples, suggesting that the structural defects in the CCNHS samples were repaired. Surprisingly, the EPR signal of the CCNHS samples was still stronger than that of $\mathrm{BCN}$, proving that there are still defects in the CCNHS samples. The combined results of elemental analysis, XPS analysis, and EPR characterization suggest that the CCNHS samples not only repaired the surface defects that facilitate the recombination of charge carriers but also retained nitrogen defects that were beneficial for the photocatalytic reactions, during the crystallization of CCNHS.

The optical characteristics and charge carrier behavior of the as-prepared samples were examined by UV-vis diffuse reflectance spectra (UV-vis DRS) and time-resolved fluorescence analysis. The UV-vis DRS of the as-prepared samples are shown in Fig. 4(a). The absorption edge of the CCNHS samples is blue-shifted compared to the CM-CN and BCN samples. This may be caused by the reduced $\pi-\pi$ interlayer stacking distance in the CCNHS frameworks due to the increase crystallization of the CCNHS samples [50]. In addition, the CCNHS samples showed a strong absorption intensity relative to the $\mathrm{CM}-\mathrm{CN}$ and
BCN samples under the full spectrum. It is thought that the increased absorption intensity in the CCNHS samples can be attributed to the multiple reflections of incident light in the porous hollow spheres and the existence of nitrogen defects, reflecting the strong light energy utilization of the CCNHS samples [51]. The recombination kinetics of photogenerated charge carriers in the as-prepared samples was studied by time-resolved fluorescence analysis, as shown in Fig. 4(b). The time-resolved fluorescence decay spectra of the as-prepared samples show multi-exponential decays, which were well fitted to the double-exponential decay model [33]. The average lifetime of charge carriers in the CCNHS samples was $9.68 \mathrm{~ns}$ (Table 2), which is shorter than that of the CM-CN samples $(12.45$ ns) and CCN samples (13.89 ns). The reduced lifetime demonstrates the rapid migration of photogenerated charge carriers on the sample surface, which is very beneficial for photocatalytic reactions [52,53]. There are two main reasons for this phenomenon. One is the increase in the crystallinity of the CCNHS sample, which reduces the structural defects on the surface of the CCNHS samples. The other is that the formation of heterojunction between heptazine-based $\mathrm{g}-\mathrm{C}_{3} \mathrm{~N}_{4}$ and triazine-based $\mathrm{g}-\mathrm{C}_{3} \mathrm{~N}_{4}$ in the $\mathrm{CM}$ sample improved the separation efficiency of photogenerated charge carriers.

The photocatalytic performance of the as-prepared samples was evaluated by the simultaneous photocatalytic hydrogen evolution and degradation of plasticizer BPA under light irra- 

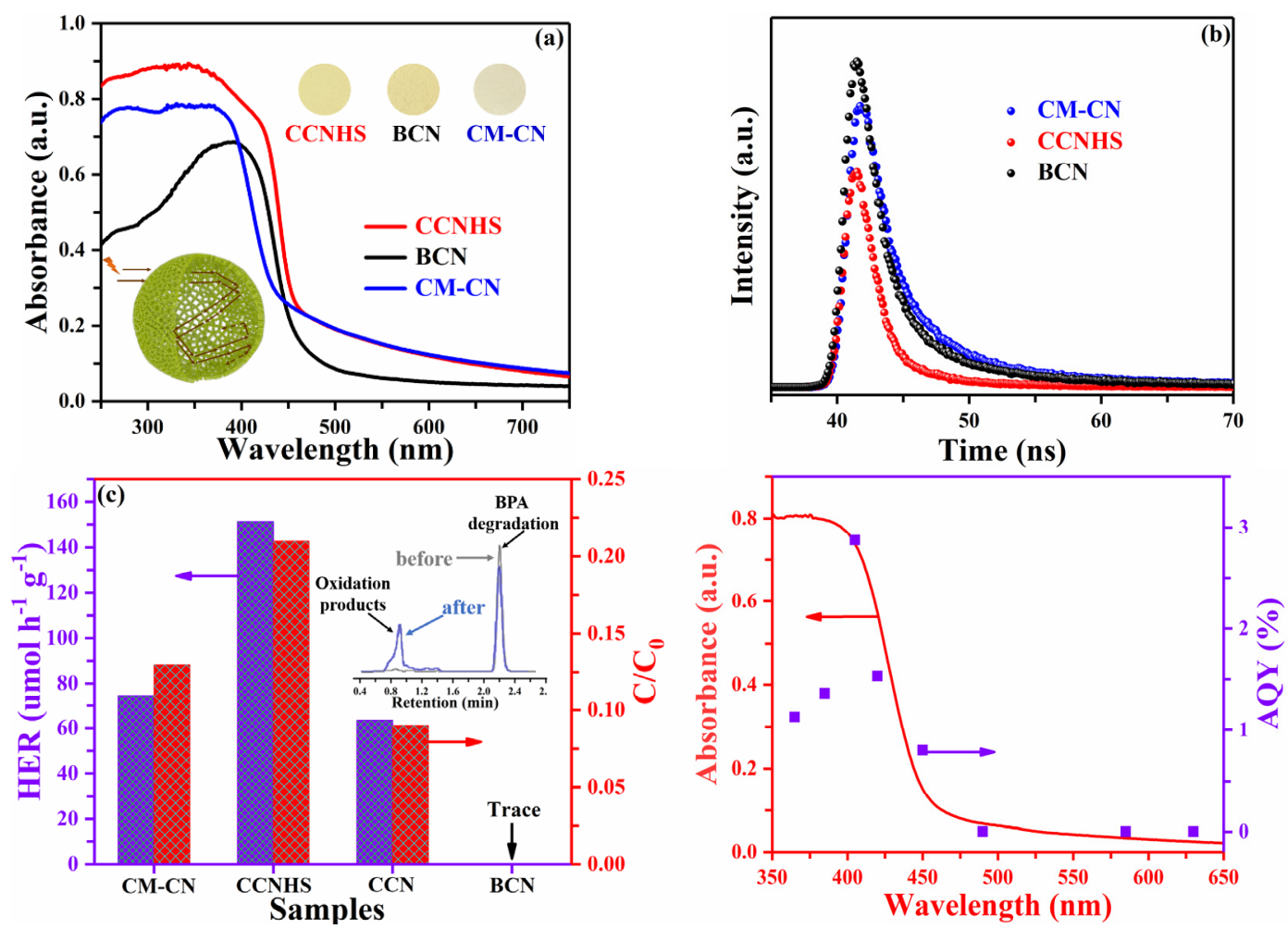

Fig. 4. (a) UV-vis DRS spectrum of as-prepared samples, the inset at the top right shows the corresponding color of as-prepared samples, the inset at the lower left shows schematic diagram of multiple reflections of light in a hollow spherical structure; (b) time-resolved PL spectra of as-prepared samples; (c) hydrogen evolution reaction (HER) rate with degradation of plasticizer BPA over the as-prepared samples under irradiation for $1 \mathrm{~h}$; (d) wavelength-dependent HER with BPA degradation over CCNHS under monochromatic light irradiation for $1 \mathrm{~h}$, the concentration of BPA solution is 10 $\mathrm{mg} \cdot \mathrm{L}^{-1}$.

diation. As shown in Fig. 4(c), the BCN samples exhibited a low photocatalytic HER due to the limitation of its own characteristics, while the CM-CN samples showed an obvious photocatalytic activity, achieving $74.5 \mu \mathrm{mol} \cdot \mathrm{h}^{-1} \cdot \mathrm{g}^{-1}$, which should be attributed to structural advantages of the porous hollow spheres. The hollow spherical structure of the CM-CN samples improved the photocatalytic activity of the sample mainly in two aspects. On the one hand, the hollow spherical structure could increase the specific surface area of the sample, and thus increase the number of active surface sites on the surface of the sample; on the other hand, it could reflect the incident light multiple times to improve the utilization of light energy. In addition, the existence of nitrogen defects can cause an increase in absorption intensity. As expected, the CCNHS samples exhibited the highest photocatalytic activity compared to the as-prepared samples, achieving $151.2 \mu \mathrm{mol} \cdot \mathrm{h}^{-1} \cdot \mathrm{g}^{-1}$, which was twice as high as that of the CM-CN samples. This phenomenon should be at-

\section{Table 2}

Fluorescence decay lifetimes and their percentages of photo-induced carriers in the BCN, CM-CN, and CCNHS samples.

\begin{tabular}{lcccc}
\hline Samples & Components & Lifetime (ns) & Intensity (\%) & $\Delta \tau(\mathrm{ns})$ \\
\hline \multirow{2}{*}{ CM-CN } & $\tau_{1}$ & 4.272 & 47.078 & \multirow{2}{*}{12.45} \\
\multirow{2}{*}{ CCNHS } & $\tau_{2}$ & 19.731 & 52.922 & \\
& $\tau_{1}$ & 3.581 & 47.506 & \multirow{2}{*}{ BCN } \\
& $\tau_{2}$ & 15.68 & 52.494 & \\
& $\tau_{1}$ & 4.554 & 43.029 & \multirow{2}{*}{13.89} \\
\hline
\end{tabular}

tributed to the structural advantages of the CCNHS samples and the formation of isotype heterojunctions between heptazine-based g- $\mathrm{C}_{3} \mathrm{~N}_{4}$ and triazine-based g- $\mathrm{C}_{3} \mathrm{~N}_{4}$. The structure of the CCNHS samples was further optimized based on the structural advantages of the $\mathrm{CM}-\mathrm{CN}$ samples. In addition to the structural advantages of $\mathrm{CM}-\mathrm{CN}$ samples, the unique structural advantages of CCNHS samples are reflected in the absence of structural defects on the surface due to the higher crystallinity of the CCNHS samples, which suppresses the possibility of surface structural defects as charge carrier recombination sites, and thus increases the migration of charge carriers. In addition, the presence of isotype heterojunctions between heptazine-based g- $\mathrm{C}_{3} \mathrm{~N}_{4}$ and triazine-based g- $\mathrm{C}_{3} \mathrm{~N}_{4}$ in the $\mathrm{CM}-\mathrm{CN}$ samples further increased the separation efficiency of charge carriers. The existence of these characteristics makes the CCNHS samples have better photocatalytic hydrogen production activity. In addition, the degradation of BPA was also examined (Fig. S9). As shown in Fig. 4(c), under light irradiation for $1 \mathrm{~h}$, the BPA degradation of the CCNHS samples achieved $21 \%$, which is higher than that of CM-CN (13\%) and CCN (9\%), which agrees with the hydrogen production results. The reason BPA can be degraded may be that its oxidation potential $(0.454$ $\mathrm{eV})$ is lower than that of oxygen $(1.23 \mathrm{eV})$; thus, BPA degradation will be preferred to oxygen production [38]. The possible degradation pathways of BPA are shown in Fig. S10. The wavelength-dependent apparent quantum yield (AQY) of the CCNHS samples was analyzed by the wavelength-dependent HER. As 
shown in Fig. 4(d), the AQY of the CCNHS samples are consistent with its UV-vis DRS. This result demonstrates that the HER is closely related to the level of light energy utilization in g- $\mathrm{C}_{3} \mathrm{~N}_{4}$-based photocatalysts. The AQY of CCNHS with the degradation of BPA was $1.53 \%$ by loading Pt as a cocatalyst under $420 \mathrm{~nm}$ light irradiation. In addition, the photocatalytic activity of the CCNHS samples using traditional sacrificial agents was also tested. As shown in Fig. S11, the photocatalytic activity of the CCNHS samples that used triethanolamine as the sacrificial agent was the strongest, followed by glycerinum, ethanediamine, and lactic acid. The AQYs corresponding to these sacrificial agents are presented in Fig. S12. The stability of the CCNHS and CM-CN samples was proven by circulating photocatalytic hydrogen production. After 4 cycles, the photocatalytic hydrogen production activity of the as-prepared samples did not decrease significantly, which proves its good stability. Finally, the photocatalytic overall water splitting over CCNHS samples was conducted and the results are shown in Fig. S14. In the absence of Pt as a cocatalyst, CCNHS samples had little photocatalytic activity in pure water. With $\mathrm{Pt}$ as a cocatalyst, the CCNHS sample showed modest photocatalytic hydrogen and oxygen production activities. The reason for this phenomenon is that the loading of Pt as a cocatalyst on the CCNHS sample can facilitate the transfer of photogenerated electrons and can act as an electron acceptor, leading to the separation of electrons and holes, which promotes the photocatalytic reduction and oxidation reactions in the conduction and valence bands, respectively [54,55].
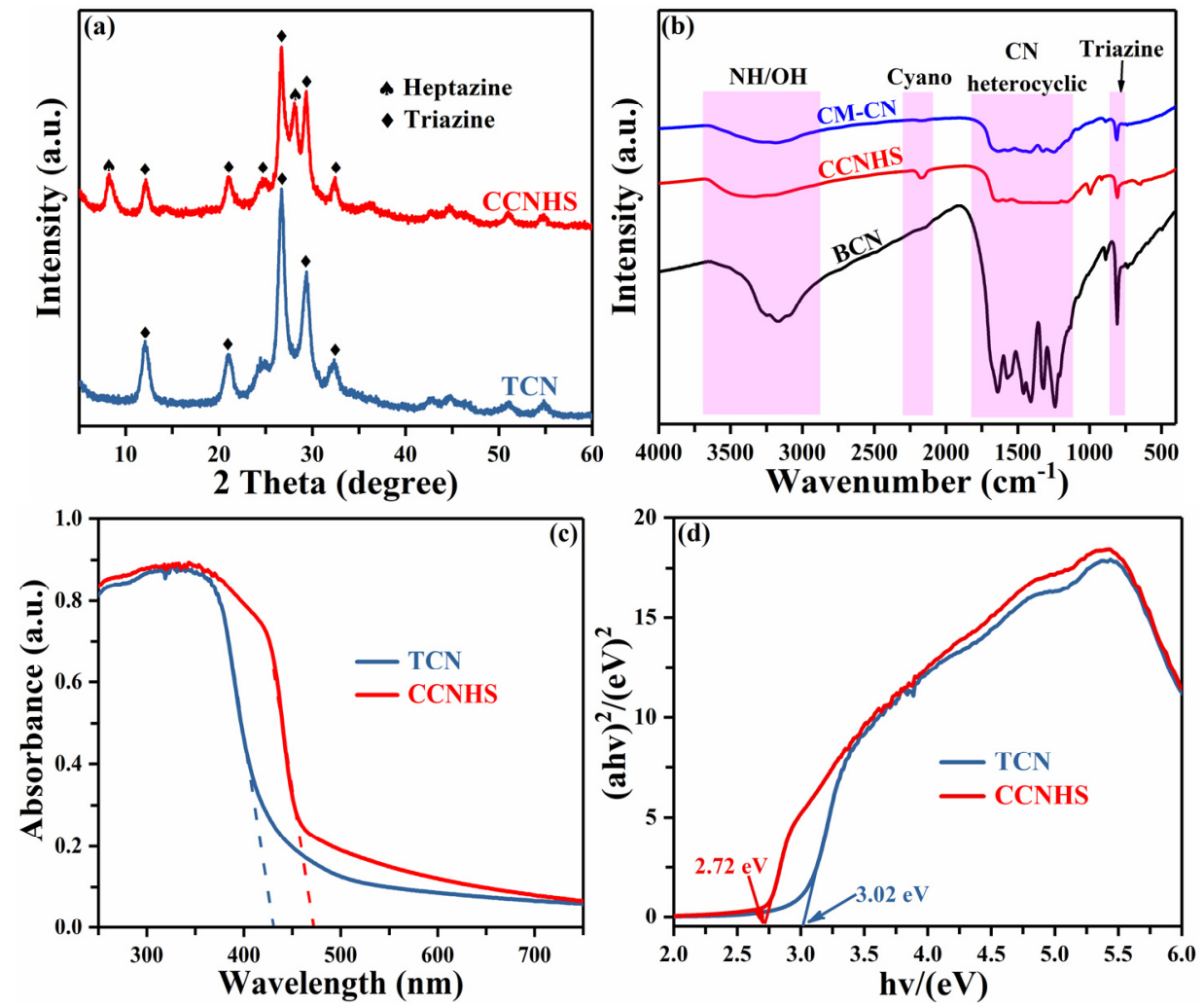

Fig. 5. (a) XRD patterns of TCN and CCNHS samples. The TCN sample shows the typical XRD pattern of triazine-based g-C ${ }_{3} \mathrm{~N}_{4}$; (b) FT-IR spectrum of TCN and CCNHS samples; (c) UV-vis DRS spectrum of TCN and CCNHS samples; (d) The estimated band gaps of TCN and CCNHS samples by Kubellka-Munk function. 

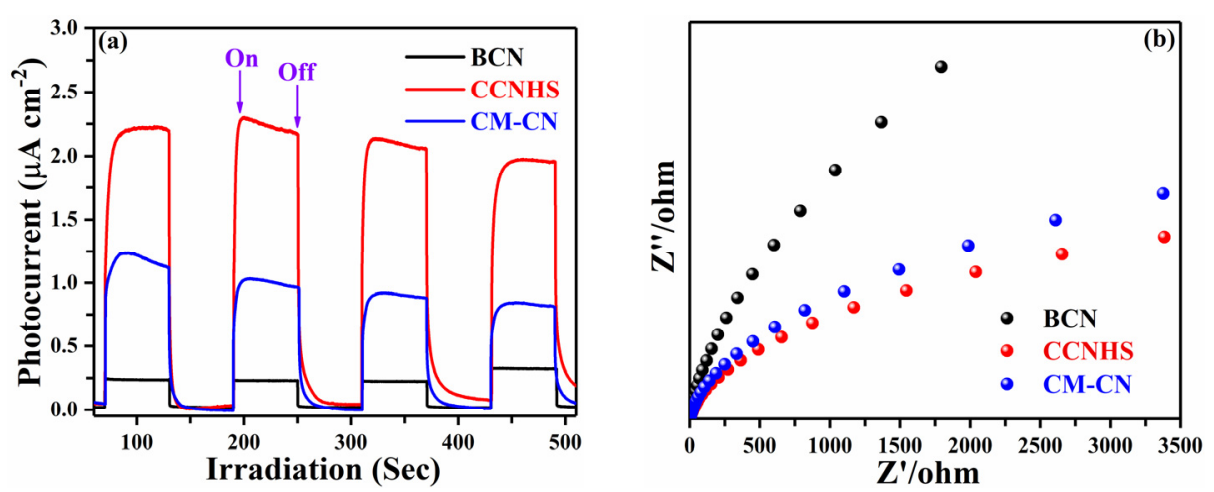

Fig. 6. The transient photocurrent responses (a) and electrochemical impedance spectroscopy (b) of as-prepared samples.

will form a heterojunction due to the staggered band gap, thereby increasing the separation efficiency of photogenerated carriers and improving the photocatalytic activity. In addition, the behavior of photogenerated carriers is further demonstrated by transient photocurrent response and electrochemical impedance spectroscopy. As shown in Fig. 6, the higher photocurrent density and smaller arc radius of the CCNHS samples proves the higher migration rate of photogenerated electron and smaller electron transfer resistance.

Based on the above results, a possible mechanism for the photocatalytic reactions of the CM-CN and CCNHS samples was proposed. As shown in Fig. 7, the hollow spherical structure of the CM-CN samples can reflect the incident light multiple times under visible-light irradiation, which improves the utilization of light energy. In addition, the porous surface structure will provide more reactive active sites for photocatalytic reactions. However, some photogenerated charge carriers will be trapped, which will cause their recombination owing to the existence of structural defects, reducing the photogenerated charge carriers involved in the photocatalytic reaction. The hollow sphere structure of the CCNHS samples can also increase light energy utilization. The nanorod structure on the surface not only further increases the specific surface area and provides additional reactive active sites but also repairs the structural defects on the sample surface, allowing more photogenerated electrons and holes to participate in the photocata- lytic reaction. In addition, the heptazine-based g- $\mathrm{C}_{3} \mathrm{~N}_{4}$ and triazine-based $\mathrm{g}-\mathrm{C}_{3} \mathrm{~N}_{4}$ in the CCNHS sample has a staggered band structure. Therefore, these two kinds of carbon nitrides will spontaneously form a built-in electric field between the heptazine-based g- $\mathrm{C}_{3} \mathrm{~N}_{4}$ and triazine-based g- $\mathrm{C}_{3} \mathrm{~N}_{4}$, improving the migration of photogenerated carriers, and thereby further enhancing the photocatalytic performance.

\section{Conclusions}

In summary, CCNHS samples were successfully synthesized by using $\mathrm{CM}$ complex as a precursor for the molten salt method. Not only was the structure of the obtained samples further optimized but also the formation of two isotypes (heptazine-based g- $\mathrm{C}_{3} \mathrm{~N}_{4}$ and triazine-based g- $\mathrm{C}_{3} \mathrm{~N}_{4}$ ) in the CCNHS samples spontaneously constructed a built-in electric field that accelerated the migration of photogenerated carriers. The simultaneous photocatalytic evolution of hydrogen and degradation of the plasticizer BPA was efficiently realized on the as-prepared samples. The prepared CCNHS samples have a HER of $151.2 \mu \mathrm{mol} \cdot \mathrm{h}^{-1} \cdot \mathrm{g}^{-1}$ and a decent degradation efficiency of BPA, which is significantly higher than that of the CM-CN and BCN samples. The enhanced photocatalytic performance of the CCNHS samples should be attributed to its optimization of the hollow structure and the establishment of the built-in electric field in highly crystalline g- $\mathrm{C}_{3} \mathrm{~N}_{4}$.

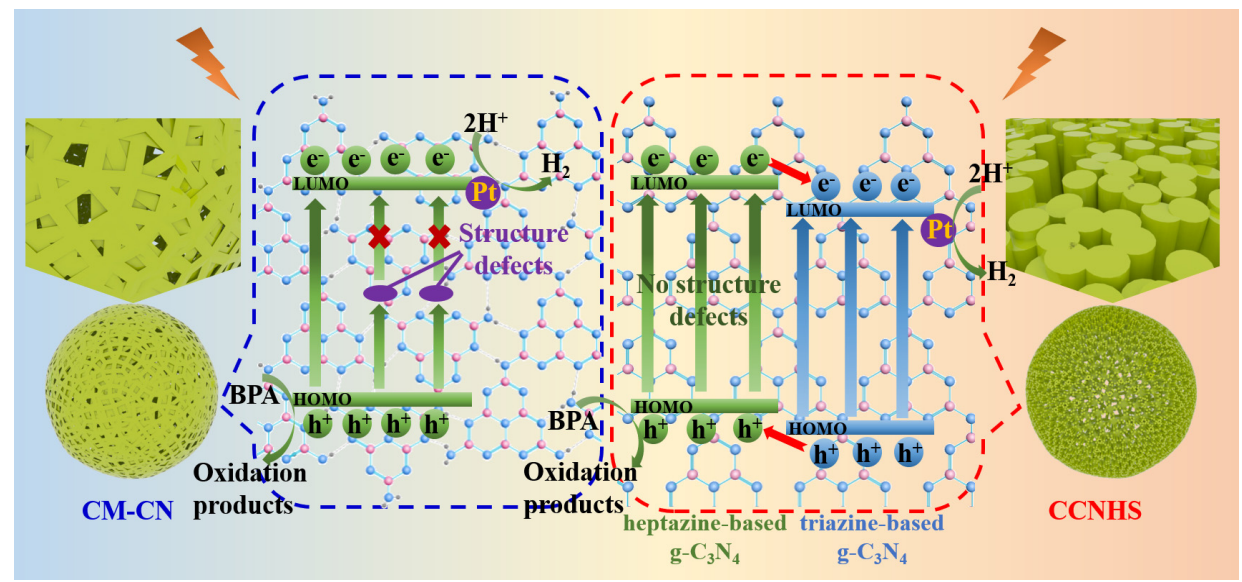

Fig. 7. Schematic of the tentative photocatalytic mechanisms of CM-CN and CCNHS samples under visible-light irradiation. 


\section{Graphical Abstract}

Chin. J. Catal., 2021, 42: 627-636 doi: 10.1016/S1872-2067(20)63684-1

\section{Highly crystalline carbon nitride hollow spheres with enhanced photocatalytic performance}

Yang Li, Dainan Zhang, Jiajie Fan, Quanjun Xiang*

University of Electronic Science and Technology of China; Huazhong Agricultural University; Zhengzhou University

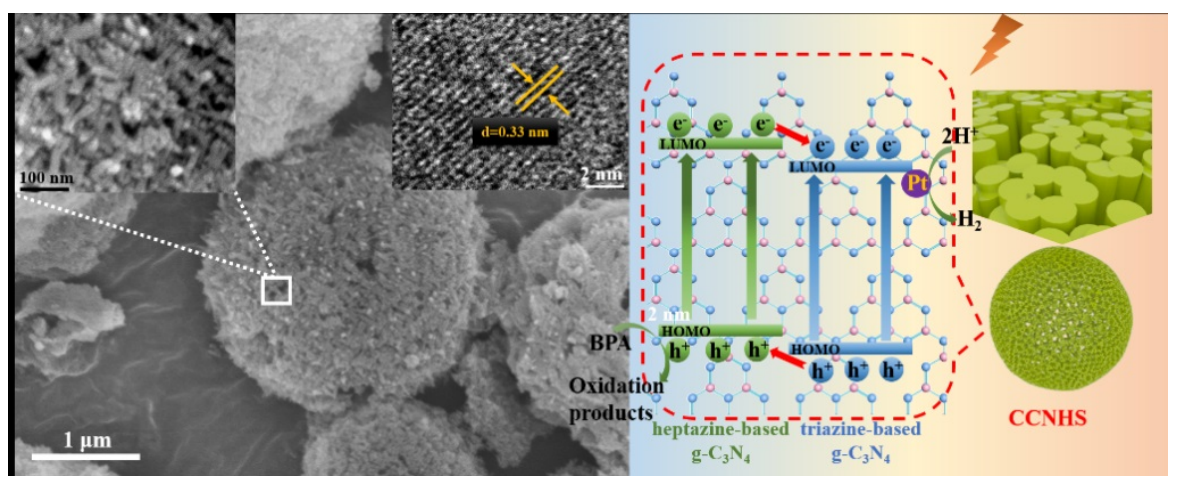

Highly crystalline g- $\mathrm{C}_{3} \mathrm{~N}_{4}$ hollow spheres, prepared by using cyanuric acid-melamine as a precursor in the molten salt method, exhibited enhanced photocatalytic hydrogen evolution with the simultaneous degradation of plasticizer Bisphenol A.

\section{References}

[1] L. Cheng, X. Li, H. W. Zhang, Q. J. Xiang, J. Phys. Chem. Lett., 2019, 10, 3488-3494.

[2] Y. L. Yang, D. N. Zhang, Q. J. Xiang, Nanoscale, 2019, 11, 18797-18805.

[3] L. Cheng, Q. J. Xiang, Y. L. Liao, H. W. Zhang, Energy Environ. Sci., 2018, 11, 1362-1391.

[4] T. P. Hu, K. Dai, J. F. Zhang, S. F. Chen, Appl. Catal. B, 2020, 269, 118844.

[5] J. Wen, J. Xie, H. Zhang, A. Zhang, Y. Liu, X. Chen, X. Li, ACS Appl. Mater. Interfaces, 2017, 9, 14031-14042.

[6] Y. Li, X. H. Feng, Z. X. Lu, H. Yin, F. Liu, Q. J. Xiang, J. Colloid Interface Sci., 2018, 513, 866-876.

[7] X. H. Wu, D. D. Gao, H. G. Yu, J. G. Yu, Nanoscale, 2019, 11, 9608-9616.

[8] Y. Huo, J. F. Zhang, K. Dai, Q. Li, J. L. Lv, G. P. Zhu, C. H. Liang, Appl. Catal. B, 2019, 241, 528-538.

[9] Q. J. Xiang, F. Li, D. N. Zhang, Y. L. Liao, H. P. Zhou, Appl. Surf. Sci., 2019, 495, 143520 .

[10] Y. H. Li, W. K. Ho, K. L. Lv, B. C. Zhu, S. C. Lee, Appl. Surf. Sci., 2018, 430, 380-389.

[11] J. Luo, Z. Lin, Y. Zhao, S. Jiang, S. Song, Chin. J. Catal., 2020, 41, 122-130.

[12] Q. L. Xu, B. C. Zhu, C. J. Jiang, B. Cheng, J. G. Yu, Solar RRL, 2018, 2, 1800006

[13] F. F. Mei, Z. Li, K. Dai, J. F. Zhang, C. H. Liang, Chin. J. Catal., 2020, 41, 41-49.

[14] K. Sun, J. Shen, Q. Liu, H. Tang, M. Zhang, S. Zulfiqar, C. Lei, Chin. J. Catal., 2019, 41, 72-81.

[15] N. Xiao, S. Li, S. Liu, B. Xu, Y. Li, Y. Gao, L. Ge, G. Lu, Chin. J. Catal., 2019, 40, 352-361.

[16] S. Zhao, Y. W. Zhang, J. S. Fang, H. Zhang, Y. Y. Wang, Y. M. Zhou, W. X. Chen, C. Zhang, ACS Sustainable Chem. Eng., 2018, 6, 8291-8299.
[17] N. Meng, J. Ren, Y. Liu, Y. Huang, T. Petit, B. Zhang, Energy Environ. Sci., 2018, 11, 566-571.

[18] H. Y. Yang, Y. M. Zhou, Y. Y. Wang, S. C. Hu, B. B. Wang, Q. Liao, H. F. Li, J. H. Bao, G. Y. Ge, S. K. Jia, J. Mater. Chem. A, 2018, 6, 16485-16494.

[19] W. N. Xing, W. G. Tu, Z. H. Han, Y. D. Hu, Q. Q. Meng, G. Chen, ACS Energy Lett., 2018, 3, 514-519.

[20] W. Iqbal, B. C. Qiu, Q. H. Zhu, M. Y. Xing, J. L. Zhang, Appl. Catal. B, 2018, 232, 306-313.

[21] Y. Li, Z. Jin, L. Zhang, K. Fan, Chin. J. Catal., 2019, 40, 390-402.

[22] L. Lin, H. Ou, Y. Zhang, X. C. Wang, ACS Catal., 2016, 6, 3921-3931.

[23] F. Li, D. N. Zhang, Q. J. Xiang, Chem. Commun., 2020, 56, 2443-2446.

[24] G. Zhang, G. Li, Z. A. Lan, L. Lin, A. Savateev, T. Heil, S. Zafeiratos, X. C. Wang, M. Antonietti, Angew. Chem. Int. Ed., 2017, 56, 13445-13449.

[25] Y. Li, D. N. Zhang, X. H. Feng, Q. J. Xiang, Chin. J. Catal., 2020, 41, 21-30.

[26] X. H. Wu, X. F. Wang, F. Z. Wang, H. G. Yu, Appl. Catal. B, 2019, 247, 70-77.

[27] Y. S. Si, Z. Z. Sun, L. M. Huang, M. Chen, L. M. Wu, J. Mater. Chem. A, 2019, 7, 8952-8959.

[28] Z. X. Zeng, H. T. Yu, X. Quan, S. Chen, S. S. Zhang, Appl. Catal. B, 2018, 227, 153-160.

[29] H. H. Ou, L. H. Lin, Y. Zheng, P. J. Yang, Y. X. Fang, X. C. Wang, Adv. Mater., 2017, 29, 1700008.

[30] G. F Ge, W. X. Guo, C. S. Song, Z. K. Zhao, ACS Appl. Mater. Interfaces, 2018, 10, 18746-18753.

[31] M. Shalom, S. Inal, C. Fettkenhauer, D. Neher, M. Antonietti, J. Am. Chem. Soc., 2013, 135, 7118-7121.

[32] S. Zhao, Y. W. Zhang, Y. M. Zhou, Y. Y. Wang, K. B. Qiu, C. Zhang, J. S. Fang, X. L. Sheng, Carbon, 2018, 126, 247-256.

[33] Y. S. Jun, Z. E. Lee, X. C. Wang, W. H. Hong, G. D. Stucky, A. Thomas, Adv. Funct. Mater., 2013, 23, 3661-3667.

[34] U. Diebold, Nat. Chem., 2011, 3, 271-272.

[35] K. Maeda, ACS Catal., 2013, 3, 1486-1503. 
[36] Y. L. Chen, G. T. Yu, W. Chen, Y. P. Liu, G. D. Li, P. W. Zhu, Q. Tao, Q. J. Li, J. W. Liu, X. P. Shen, H. Li, X. R. Huang, D. J. Wang, T. Asefa, X. X. Zou, J. Am. Chem. Soc., 2017, 139, 12370-12373.

[37] R. Ma, S. Zhang, P. C. Gu, T. Wen, A. Khan, S. J. Li, B. F. Li, S. H. Wang, X. K. Wang, ACS Sustainable Chem. Eng., 2019, 7, 9699-9708.

[38] X. H. Jiang, L. C. Wang, F. Yu, Y. C. Nie, Q. J. Xing, X. Liu, Y. Pei, J. P. Zou, W. L. Dai, ACS Sustainable Chem. Eng., 2018, 6, 12695-12705.

[39] H. Z. Zhang, J. F. Banfield, J. Phys. Chem. B, 2000, 104, 3481-3487.

[40] A. A. Gribb, J. F. Banfield, Am. Mineral., 1997, 82, 717-728.

[41] L. H. Lin, Z. Y. Yu, X. C. Wang, Angew. Chem. Int. Ed., 2019, 28, 2-14.

[42] K. He, J. Xie, M. Li, X. Li, Appl. Surf. Sci., 2018, 430, 208-217.

[43] A. L. Jin, X. Liu, M. R. Li, Y. S. Jia, C. F. Chen, X. S. Chen, ACS Sustainable Chem. Eng., 2019, 7, 5122-5133.

[44] M. K. Bhunia, K. Yamauchi, K. Takanabe, Angew. Chem. Int. Ed., 2014, 53, 11001-11005.

[45] L. H. Lin, W. Ren, C. Wang, A. M. Asiri, J. Zhang, X. C. Wang, Appl. Catal. B, 2018, 231, 234-241.

[46] C. F. Yang, W. Teng, Y. H. Song, Y. J. Cui, Chin. J. Catal., 2018, 39, 1615-1624.

[47] C. Yang, S. Zhang, Y. Huang, K. Lv, S. Fang, X. Wu, Q. Li, J. Fan, Appl.
Surf. Sci., 2020, 505, 144654.

[48] X. Dou, Z. Lin, H. Chen, Y. Zheng, C. Lu, J. M. Lin, Chem. Commun., 2013, 49, 5871-5873.

[49] P. F. Xia, M. J. Liu, B. Cheng, J. G. Yu, L. Y. Zhang, ACS Sustainable Chem. Eng., 2018, 6, 8945-8953.

[50] M. Zhou, P. J. Yang, R. S. Yuan, A. M. Asiri, M. Wakeel, X. C. Wang, ChemSusChem, 2017, 10, 4451-4456.

[51] J. S. Zhang, J. H. Sun, K. Maeda, K. Domen, P. Liu, M. Antonietti, X. Z. Fu, X. C. Wang, Energy Environ. Sci., 2011, 4, 675-678.

[52] W. M. Xu, X. H. An, Q. G. Zhang, Z. Li, Q. H. Zhang, Z. Yao, X. K. Wang, S. Wang, J. T. Zheng, J. Zhang, W. T. Wu, M. B. Wu, ACS Sustainable Chem. Eng., 2019, 7, 12351-12357.

[53] K. Schwinghammer, M. B. Mesch, V. Duppel, C. Ziegler, J. Senker, B. V. Lotsch, J. Am. Chem. Soc., 2014, 136, 1730-1733.

[54] L. Cheng, D. N. Zhang, Y. L. Liao, H. W. Zhang, Q. J. Xiang, Solar RRL, 2019, 3, 1900062.

[55] G. G. Zhang, Z. A Lan, L. H. Lin, S. Lin, X. C. Wang, Chem. Sci., 2016, 7, 3062-3066.

[56] Y. Li, Gong, F. Q. Zhou, X. H. Feng, J. J. Fan, Q. J. Xiang, Appl. Catal. B, 2020, 268, 118381.

\title{
高结晶氮化碳空心球的制备及其增强光催化产氢活性
}

\author{
李 阳 ${ }^{\mathrm{a}, \mathrm{b}}$, 张岱南 ${ }^{\mathrm{a}}$, 范佳杰 ${ }^{\mathrm{c}}$, 向全军 ${ }^{\mathrm{a},}{ }^{*}$ \\ a电子科技大学电子科学与工程学院, 电子薄膜与集成器件国家重点实验室, 四川成都610054 \\ b华中农业大学资源与环境学院, 湖北武汉 430070 \\ c 郑州大学材料科学与工程学院, 河南郑州 450002
}

摘要: 石墨烯型氮化碳 $\left(\mathrm{g}-\mathrm{C}_{3} \mathrm{~N}_{4}\right)$ 已经成为解决环境污染和能源危机问题的较为理想的光催化剂, 但由于其较低的比表面积 和较高的光生载流子重组效率而表现出较弱的光催化活性. 因此, 研究者们已经提出了许多策略, 例如纳米结构设计, 杂 原子掺杂和增加结晶度, 用来克服氮化碳的这些缺点, 从而提高其光催化性能. 其中, 引起了较多关注的是增加 $\mathrm{g}-\mathrm{C}_{3} \mathrm{~N}_{4}$ 的结 晶度, 因为晶化 $\mathrm{g}-\mathrm{C}_{3} \mathrm{~N}_{4}(\mathrm{CCN})$ 的内层堆积密度高, 外层结构缺陷少, 可以提供更快的光生载流子迁移效率, 从而增加参与光 催化反应的光生电子和空穴. 即便如此, 通过常规方法制备的晶化 $\mathrm{g}-\mathrm{C}_{3} \mathrm{~N}_{4}$ 依然显示出不规则的形貌和较低的比表面积. 基 于此, 本文以氰尿酸-三聚氰胺 $(\mathrm{CM})$ 超分子自组装混合物作为前驱体, 通过熔盐法成功地制备了高结晶度的 $\mathrm{g}-\mathrm{C}_{3} \mathrm{~N}_{4}$ 空心球 (CCNHS). 采用XRD、FTIR、 ${ }^{13} \mathrm{C}$ 固相CP-MAS NMR、XPS和时间分辨PL谱对CCNHS样品的基本性质进行了表征，并通过 SEM、HRTEM、氮吸附-脱附和紫外-可见DRS光谱对CCNHS样品的形貌结构进行了表征. 结果表明, CCNHS样品呈现出 由纳米棒组成的非常规则的空心球结构, 因而表现出比传统CCN样品更大的比表面积以及更强的光利用效率. CCNHS样 品XRD谱出现晶化氮化碳的特征峰; 其HRTEM照片出现了对应晶化氮化碳的 $0.33 \mathrm{~nm}$ 晶格条纹; FFT衍射斑点的出现以及 光吸收能力的增强进一步证明了CCNHS样品结晶度的提高. XPS谱元素分析以及EPR谱结果表明, CCNHS样品中还存在 有利于提高光生电子转移的氮空位. 光电流、阻抗谱以及与三嗪晶化氮化碳的对比结果证明, CCNHS样品中存在内在电 场. 同时, 采用具有一定毒性的双酚A增塑剂替代了从粮食中提取出来的传统醇类牺牲剂, 既保证了对有毒污染物的降解, 也减少了粮食的浪费. 即使以难降解的双酚A作为牺牲剂, CCNHS样品在降解双酚A(降解率为 $21 \%$ )的同时, 依然表现出较 好的光催化产氢活性 $\left(151.2 \mu \mathrm{mol} \cdot \mathrm{h}^{-1} \cdot \mathrm{g}^{-1}\right)$. 本文为超分子自组装的结构优化以及晶化氮化碳的改善提供了新视角.

关键词: 晶化; 空心球; 石墨化氮化碳; 光催化析氢; 光催化降解；增塑剂

收稿日期: 2020-05-26. 接受日期: 2020-07-11. 上网日期: 2020-09-05.

*通讯联系人. 电话/传真: (028)83207063; 电子信箱:xiangqj@uestc.edu.cn

基金来源：国家自然科学基金(51672099,21403079); 四川省科技计划(2019JDRC0027); 中央高校基金(2017-QR-25).

本文的电子版全文由Elsevier出版社在ScienceDirect上出版(http://www.sciencedirect.com/science/journal/18722067). 